\title{
Perceived need to increase physical activity levels among adults at high risk of type 2 diabetes. A cross-sectional analysis within a community- based diabetes prevention project FIN-D2D
}

Kati Vähäsarja ${ }^{1 *}$, Sanna Salmela', Jari Villberg ${ }^{1}$, Pauli Rintala², Mauno Vanhala ${ }^{3,4,5}$, Timo Saaristo ${ }^{6,7}$, Markku Peltonen ${ }^{8}$, Sirkka Keinänen-Kiukaanniemi ${ }^{9}{ }^{10,11}$, Eeva Korpi-Hyövältii ${ }^{12}$, Urho M Kujala ${ }^{1}$, Leena Moilanen ${ }^{13}$, Leo Niskanen ${ }^{14,15}$, Heikki Oksa ${ }^{7,16}$ and Marita Poskiparta ${ }^{1}$

\begin{abstract}
Background: Increased physical activity is a cornerstone of type 2 diabetes prevention. The perception of a need to change is considered essential in behaviour change processes. However, the existing literature on individuals' perceived need to change health behaviour is limited. In order to improve understanding of diabetes prevention through increased physical activity levels (PAL), we assessed factors associated with perceiving a need to increase PAL among adults at high risk of diabetes.
\end{abstract}

Methods: Opportunistic screening was used within a primary-care based lifestyle intervention covering 10149 men and women at high risk of type 2 diabetes. Data were obtained at baseline visits. The explored determinants were demographic, anthropometric/clinical, behavioural and psychosocial characteristics, along with four categories of PAL awareness. Logistic regression was used in the analysis.

Results: $74 \%$ of men ( $n=2577)$ and $76 \%$ of women $(n=4551)$ perceived a need to increase their PAL. The participants most likely to perceive this need were inactive, had a larger waist circumference, rated their PAL as insufficient, and were at the contemplation stage of change. Smoking, elevated blood pressure, dyslipidaemia, and a family history of diabetes were not associated with this perception. The likelihood was also greater among women with less perceived fitness and less education. Demographic factors other than education did not determine participants' perceived need to increase PAL. PAL overestimators were less likely to perceive the need to increase their PAL than realistic inactive participants.

Conclusions: Subjective rather than objective health factors appear to determine the perception of a need to increase PAL among adults at high risk of diabetes. Client perceptions need to be evaluated in health counselling in order to facilitate a change in PAL. Practical descriptions of the associations between metabolic risk factors, PAL, and diabetes are needed in order to make the risk factors concrete for at-risk individuals.

Keywords: Physical activity, Exercise, Behaviour change, Perception, Awareness, Type 2 diabetes, Prevention, FIND2D, Lifestyle intervention

\footnotetext{
* Correspondence: kati.vahasarja@jyu.fi

'Department of Health Sciences, University of Jyväskylä, Jyväskylä 40014, Finland

Full list of author information is available at the end of the article
} 


\section{Background}

Extensive literature has indicated that type 2 diabetes can be prevented or delayed by increased levels of physical activity (PAL) [1-8]. People with diabetes are claimed to be least ready to increase their physical activity levels (PAL), to a greater degree than people without diabetes or people with heart disease, elevated blood pressure, or dyslipidaemia [9]. However, inclinations toward PAL behaviour change among the highrisk population remain imperfectly understood. It has been suggested $[10,11]$ that perceived risk will increase protective behaviour. Indeed, the vast majority of participants at risk of diabetes have been reported as intending to increase their PAL [12], or as having tried to increase their PAL during the past twelve months [13]. However, it has been reported elsewhere that diabetes risk perception is not associated with physical activity intention among adults at risk of type 2 diabetes [14], and that persons with a higher diabetes risk perception do not have a greater intention than others to increase their PAL [15].

An individual's perceived need to change behaviour is regarded as a pre-step toward an intention [16-18]. However, only a few studies have assessed the perceived need to change health behaviour: three studies found perceived need to significantly predict the intention to improve diet [19-21], whereas no association was found between the perceived need and an intention to exercise [22]. The authors examined the perceived need to change health behaviour as a continuum within the theory of planned behaviour [23], taking the view that perceived need reflects perceived benefits, but that the perceptions of need and benefits are distinct. It was assumed that a person may have a positive attitude toward a behaviour, but not necessarily feel a need to change the behaviour if (i) the costs outweigh the benefits, (ii) the outcome of the behaviour is not valued highly by the person, or (iii) if the outcome is believed to be achievable by other means.

The concept of perceived need has been also associated with the transtheoretical theory (TTM) [17,24]. TTM suggests that individuals go through five distinct stages according to their motivational readiness to change behaviour. Individuals at the precontemplation stage are not regularly physically active, do not view their behaviour as a problem, and may therefore not perceive the need to change their behaviour. Once an individual becomes aware of his/her problem behaviour he/ she may shift to the contemplation stage and continue to the preparation, action, and maintenance stages.

The third approach emphasising the role of perceived need in the change process is a counselling approach called motivational interviewing (MI) [18,25]. MI focuses primarily on enhancing the intrinsic motivation to change risk behaviour among individuals at the precontemplation and contemplation stages (who are reluctant or hesitative about the change). MI proposes that motivation to change increases in parallel with the individual's own arguments regarding his/her perceived need, desire, ability, and reasons for change. These arguments strongly predict commitment, which in turn predicts change [26-28].

TTM [29-32] and MI [33,34] have both been widely applied to physical activity, and to type 2 diabetes prevention $[35,36]$. Even though these approaches regard a person's perceived need to change as an essential preparatory step for the intention and commitment to behaviour change, the concept has rarely been examined. Similarly, the existing literature on the correlates of the pre-contemplation stage is limited, and has tended to focus mainly on psychosocial aspects $[15,37,38]$.

Perceiving the need to increase PAL is crucial for a population at high risk of type 2 diabetes. Thus, it is important to explore which factors determine this need. We examined demographic, anthropometric/clinical, behavioural, and psychosocial factors as determinants of this need perception among adults at high risk of type 2 diabetes. Since previous studies have shown misperception of one's own physical activity level to be a common phenomenon, and also to be associated with physical activity intention [37,39-43], we further examined the perceived need to increase PAL across four categories of physical activity awareness groups.

\section{Methods}

\section{Study design and participants}

FIN-D2D, an implementation project within a national programme for the prevention of type 2 diabetes, was conducted by the Finnish Diabetes Association in five Finnish hospital districts covering a population of 1.5 million $[44,45]$. The collaborating bodies were the $\mathrm{Na}-$ tional Public Health Institute, the Ministry of Social Affairs and Health and the FIN-D2D Study Group. The specific aims were to improve the screening of people at risk of diabetes and to detect undiagnosed diabetes. The programme included intensified interventions among high-risk individuals as part of normal clinical practice (for the full study protocol see $[46,47]$ ).

Opportunistic screening was conducted in health care centres and pharmacies, and at various public venues and events (e.g. health fairs), in order to screen individuals at high risk of type 2 diabetes. A modified Finnish diabetes risk score (FINDRISC) was used for the screening process [48]. Individuals were referred to primary care for lifestyle intervention on a voluntary basis if they met any of the following criteria (i) a FINDRISC test score $\geq 15$, (ii) a history of gestational diabetes, (iii) a history of impaired glucose tolerance or impaired fasting 
Table 1 Characteristics of the study population

\begin{tabular}{ll}
$\begin{array}{l}\text { Men } \\
(n=2557)\end{array}$ & $\begin{array}{l}\text { Women } \\
(n=4551)\end{array}$ \\
\cline { 1 - 1 }$\%$ & $\%$
\end{tabular}

\begin{tabular}{|c|c|c|}
\hline \multicolumn{3}{|l|}{ Age (years) } \\
\hline$<45$ & 14 & 13 \\
\hline $45-54$ & 32 & 30 \\
\hline $55-64$ & 20 & 21 \\
\hline$\geq 65$ & 34 & 35 \\
\hline \multicolumn{3}{|l|}{ Marital status ${ }^{* * *}$} \\
\hline Married/cohabiting & 77 & 72 \\
\hline Other & 23 & 28 \\
\hline \multicolumn{3}{|l|}{ Educational level } \\
\hline Low & 41 & 39 \\
\hline Intermediate & 50 & 53 \\
\hline High & 9 & 9 \\
\hline \multicolumn{3}{|l|}{ Occupational status*** } \\
\hline Manual work & 34 & 9 \\
\hline Non-manual work & 25 & 44 \\
\hline Retired & 34 & 35 \\
\hline Not employed & 7 & 13 \\
\hline Family history of diabetes ${ }^{1 * * *}$ & 57 & 66 \\
\hline Elevated blood pressure $e^{2 * * *}$ & 88 & 82 \\
\hline Dyslipidaemia ${ }^{3 * * *}$ & 30 & 40 \\
\hline Obesity ${ }^{4 * * *}$ & 57 & 63 \\
\hline \multicolumn{3}{|l|}{ Waist circumference ${ }^{5 * * *}$} \\
\hline Normal & 8 & 3 \\
\hline Elevated risk & 22 & 10 \\
\hline High risk & 70 & 87 \\
\hline Currently smoking ${ }^{6 * * *}$ & 23 & 15 \\
\hline Physically inactive $^{7}$ & 65 & 65 \\
\hline \multicolumn{3}{|l|}{ Self-rated fitness* } \\
\hline Low & 22 & 25 \\
\hline Satisfactory & 50 & 48 \\
\hline High & 28 & 27 \\
\hline \multicolumn{3}{|l|}{ Stage of change ${ }^{* * *}$} \\
\hline Precontemplation & 11 & 7 \\
\hline Contemplation & 29 & 24 \\
\hline Preparation & 39 & 46 \\
\hline Action & 12 & 14 \\
\hline Maintenance & 9 & 9 \\
\hline Physical activity level perceived as sufficient* & 33 & 30 \\
\hline $\begin{array}{l}\text { Perceives the need to increase physical } \\
\text { activity level }\end{array}$ & 74 & 76 \\
\hline
\end{tabular}

${ }^{1}$ At least one of the first-degree relatives had diabetes (type 1 or 2).

${ }^{2}$ Systolic blood pressure $\geq 130 \mathrm{mmHg}$ and/or diastolic blood pressure $\geq 85 \mathrm{mmHg}$.

${ }^{3} \mathrm{HDL}<1.03 \mathrm{mmol} / \mathrm{l}$ (men), $<1.29 \mathrm{mmol} / \mathrm{l}$ (women); LDL $\geq 3 \mathrm{mmol} / \mathrm{l}$ or/and triglycerides $\geq 1.7 \mathrm{mmol} / \mathrm{l}$, or medication for these lipid abnormalities.

${ }^{4}$ Body mass index (BMI) $\geq 30 \mathrm{~kg} / \mathrm{m}^{2}$.

${ }^{5}$ Normal: $<94 \mathrm{~cm}(\mathrm{~m}),<80 \mathrm{~cm}(\mathrm{w})$; elevated risk: $94-101 \mathrm{~cm}(\mathrm{~m}), 80-87 \mathrm{~cm}$ (w); high risk: $\geq 102 \mathrm{~cm}(\mathrm{~m}), \geq 88 \mathrm{~cm}(\mathrm{w})$.

${ }^{6}$ Includes occasional and regular smokers.

${ }^{7}$ Engaging in physical exercise $<30$ minutes three times a week.

${ }^{*} p<0.05$ (for the statistical difference between the sexes).

** $p<0.01$.

*** $p<0.001$.

glucose, or (iv) a history of coronary heart disease. After identification, consenting high-risk individuals attended health check-ups conducted in primary health care units as part of standard care. Individuals received written information on the FIN-D2D and their participation in the project within normal primary care activities.

The present study analysed the baseline data from the FIN-D2D intervention, collected in 400 primary health care centres and occupational health clinics between 2004 and 2008. Altogether, 10149 individuals aged 1887 participated in the baseline assessments. Out of these, 9984 individuals finally met the criteria for being at high risk. Glucose tolerance [49] was assessed with an oral glucose tolerance test (OGTT) among 8353 of the participants. Individuals with previously-diagnosed type 2 diabetes, and screen-detected type 2 diabetes were excluded from the analysis, leaving 7128 individuals in the analysis. The participant characteristics are presented in Table 1.

\section{Measurements}

The participants completed a questionnaire (questionnaire 1 , issues regarding information on e.g. health behaviour and health status) and underwent health examinations. After these assessments the participants discussed with a nurse their health examination results, current health status, and health behaviour, in relation to current health recommendations and the risk of diabetes.

\section{Perceived need to increase PAL}

During the nurse-participant discussion, the nurse asked participants whether they perceived a need to change their health behaviours (to increase PAL, make changes in diet, quit smoking, reduce alcohol consumption, or lose weight in general). The nurses recorded the participants' behaviour change targets within the structured questionnaire (response options "no need perceived"/ "need perceived", for each item separately) according to the participant's perception (questionnaire 2). The evaluation form (based on TTM and MI) was developed especially for the FIN-D2D intervention [46]. 


\section{Demographic factors}

The participants were classified into four age-group categories (see Table 1). The highest level of education was asked, with subsequent regrouping into three educational levels. The occupational status category originally included seven response-options, but these were subsequently regrouped into four categories. Marital status was also assessed.

\section{Anthropometric and clinical risk factors}

A family history of diabetes was assessed via a selfreport. If at least one of the first-degree relatives (father, mother, or sibling) had diabetes (type 1 or type 2), family history was considered to be positive. Height and weight (usual light clothing, no shoes) were measured by the nurse for calculation of BMI $\left(\mathrm{kg} / \mathrm{m}^{2}\right)$. The participants were classified into two groups by BMI $\left(<30 \mathrm{~kg} / \mathrm{m}^{2}\right.$ and $\geq 30 \mathrm{~kg} / \mathrm{m}^{2}$ ). Waist circumference was measured to the nearest centimetre and classified into three groups: normal (men $<94 \mathrm{~cm}$, women $<80 \mathrm{~cm}$ ), elevated risk (men 94-101 cm, women 80-87 cm), and high risk (men $\geq 102 \mathrm{~cm}$, women $\geq 88 \mathrm{~cm}$ ). Blood pressure $(\mathrm{mmHg}$, to the nearest $1 \mathrm{mmhg}$ ) was measured twice from the right arm in sitting position (with at least a 1-min interval). The mean reading was recorded. Blood pressure was classified into two groups: normal, and elevated (systolic $\geq 130 \mathrm{mmHg}$ and/or diastolic $\geq 85 \mathrm{mmHg}$ ) blood pressure. Plasma lipids and lipoproteins were determined locally from fasting venous plasma samples using enzymatic methods. Participants with impaired values of HDL $(<1.03 \mathrm{mmol} / \mathrm{l}$ in men, $<1.29 \mathrm{mmol} / \mathrm{l}$ in women), LDL $(\geq 3 \mathrm{mmol} / \mathrm{l}))$, or triglycerides $(\geq 1.7 \mathrm{mmol} / \mathrm{l})$, or medication for these lipid abnormalities were combined into a group called "dyslipidaemia". The cut-off points used in the analysis were all based on international definitions [50,51].

\section{Behavioural factors}

Self-reported PAL was assessed with following questions (i) "How many times a week do you engage in leisuretime physical exercise causing you at least moderate sweating or breathlessness?" (ii) "For how long do you usually engage in leisure-time physical exercise at a time?". The respondents were also asked to describe with structured descriptions their leisure-time physical activity during a typical week. Here the response options ranged from inactivity through light physical activity, and further to moderate/vigorous physical activity. The participants were classified as active if they did at least 30 minutes of physical exercise three times a week, and if they described the intensity of their usual leisure physical activity as at least moderate. All other participants were classified as inactive. Current smoking (including regular and occasional smoking) was assessed and dichotomised (yes/no).

\section{Psychosocial factors}

Participants rated their physical fitness via five response options ranging from very high to very low. Extremes were combined with the nearest options. Participants also rated their readiness to increase their PAL level via a 5-item question. Here the response options covered stages of change from the precontemplation to the maintenance stage. Furthermore, participants rated their current PAL as sufficient or as insufficient for maintaining their health and physical fitness (yes/no).

\section{Physical activity awareness}

PAL awareness was assessed by comparing the participants' self-perceived sufficiency of their PAL with their self-reported PAL. Participants were classified into four physical activity awareness categories; realistic active (active by self-reported PAL, and perceiving their own PAL as sufficient), overestimators (inactive by self-report, but perceiving their own PAL as sufficient), realistic inactive (inactive by self-report, and perceiving their own PAL as insufficient) and underestimators (active by self-report, but perceiving their own PAL as insufficient).

\section{Statistical methods}

SPSS for Windows (14.1) was used for the statistical analysis. Descriptive statistics were used to describe the sample. Pearson's Chi Square tests were used to analyse differences between the groups and for a preliminary assessment of the associated factors. A multivariable logistic regression model was used to evaluate the association between a perceived need to increase PAL and demographic factors, anthropometric and clinical risk factors, behavioural factors, and psychosocial factors (Table 2). The results are presented as adjusted odds ratios (OR) and 95\% confidence intervals (CI). Medication for a risk condition was taken as equivalent to having a risk condition. The category of lowest risk with regard to type 2 diabetes was used as a reference group for all variables. A separate logistic regression was used to determine the associations of physical activity awareness groups with the perceived need to increase PAL (Table 3).

\section{Ethical considerations}

The Ministry of Social Affairs and Health in Finland gave permission to the National Institute for Health and Welfare (formerly National Public Health Institute) to collect the data from health care units for evaluation purposes. In addition, the Institutional Review Board (IRB) of the National Institute for Health and Welfare approved the study. As lifestyle interventions were conducted as part of normal routine in primary health care 
Table 2 Multivariable logistic regression model for perceived need to increase physical activity levels (PAL) among adults at high risk of diabetes $(n=7128)$ by selected variables

\begin{tabular}{|c|c|c|c|c|c|c|}
\hline & \multicolumn{3}{|l|}{ Men } & \multicolumn{3}{|c|}{ Women } \\
\hline & $\overline{\mathrm{OR}}$ & $(95 \% \mathrm{Cl})$ & $p$ & $\overline{O R}$ & $(95 \% \mathrm{Cl})$ & $p$ \\
\hline \multicolumn{7}{|l|}{ Age (years) } \\
\hline$<45$ & 1.00 & & & 1.00 & & \\
\hline $45-54$ & 1.05 & $(0.65-1.66)$ & 0.892 & 0.79 & $(0.55-1.15)$ & 0.213 \\
\hline $55-64$ & 0.68 & $(0.41-1.12)$ & 0.132 & 0.76 & $(0.51-1.14)$ & 0.187 \\
\hline$\geq 65$ & 0.90 & $(0.51-1.58)$ & 0.714 & 0.69 & $(0.44-1.08)$ & 0.101 \\
\hline \multicolumn{7}{|l|}{ Marital status } \\
\hline Married/cohabiting & 1.00 & & & 1.00 & & \\
\hline Other & 0.95 & $(0.68-1.32)$ & 0.771 & 0.95 & $(0.75-1.20)$ & 0.665 \\
\hline \multicolumn{7}{|l|}{ Educational level } \\
\hline High & 1.00 & & & 1.00 & & \\
\hline Intermediate & 0.63 & $(0.35-1.13)$ & 0.118 & 1.46 & $(1.01-2.09)$ & 0.042 \\
\hline Low & 0.60 & $(0.33-1.09)$ & 0.092 & 1.49 & $(1.01-2.19)$ & 0.043 \\
\hline \multicolumn{7}{|l|}{ Occupational status } \\
\hline Non-manual work & 1.00 & & & 1.00 & & \\
\hline Manual work & 0.91 & $(0.62-1.33)$ & 0.628 & 0.78 & $(0.54-1.15)$ & 0.209 \\
\hline Retired & 0.70 & $(0.45-1.10)$ & 0.119 & 0.84 & $(0.62-1.16)$ & 0.295 \\
\hline Not employed & 0.75 & $(0.42-1.35)$ & 0.343 & 0.90 & $(0.64-1.27)$ & 0.543 \\
\hline \multicolumn{7}{|c|}{ Family history of diabetes ${ }^{1}$} \\
\hline No & 1.00 & & & 1.00 & & \\
\hline Yes & 0.98 & $(0.75-1.28)$ & 0.865 & 1.09 & $(0.88-1.36)$ & 0.422 \\
\hline \multicolumn{7}{|c|}{ Elevated blood pressure ${ }^{2}$} \\
\hline No & 1.00 & & & 1.00 & & \\
\hline Yes & 0.95 & $(0.62-1.46)$ & 0.821 & 0.84 & $(0.64-1.10)$ & 0.208 \\
\hline \multicolumn{7}{|l|}{ Dyslipidaemia $^{3}$} \\
\hline No & 1.00 & & & 1.00 & & \\
\hline Yes & 1.14 & $(0.85-1.55)$ & 0.384 & 1.11 & $(0.90-1.38)$ & 0.324 \\
\hline \multicolumn{7}{|c|}{ Body mass index $\left(\mathrm{kg} / \mathrm{m}^{2}\right)$} \\
\hline$<30$ & 1.00 & & & 1.00 & & \\
\hline$\geq 30$ & 1.31 & $(0.94-1.83)$ & 0.117 & 1.21 & $(0.95-1.55)$ & 0.117 \\
\hline \multicolumn{7}{|l|}{ Waist circumference ${ }^{4}$} \\
\hline Normal & 1.00 & & & 1.00 & & \\
\hline Elevated & 1.34 & $(0.80-2.25)$ & 0.273 & 1.37 & $(0.73-2.56)$ & 0.322 \\
\hline High risk & 1.83 & $(1.07-3.13)$ & 0.028 & 2.72 & $(1.50-4.93)$ & $<0.001$ \\
\hline \multicolumn{7}{|l|}{ Smoking } \\
\hline No & 1.00 & & & 1.00 & & \\
\hline Yes $^{5}$ & 1.05 & $(0.75-1.47)$ & 0.783 & 0.77 & $(0.58-1.04)$ & 0.084 \\
\hline \multicolumn{7}{|l|}{ Physically active ${ }^{6}$} \\
\hline Yes & 1.00 & & & 1.00 & & \\
\hline No & 1.46 & $(1.07-1.98)$ & 0.017 & 1.57 & $(1.57-1.98)$ & $<0.001$ \\
\hline \multicolumn{7}{|l|}{ Self-rated fitness } \\
\hline High & 1.00 & & & 1.00 & & \\
\hline Satisfactory & 1.04 & $(0.75-1.42)$ & 0.833 & 1.30 & $(1.02-1.66)$ & 0.034 \\
\hline
\end{tabular}


Table 2 Multivariable logistic regression model for perceived need to increase physical activity levels (PAL) among adults at high risk of diabetes $(n=7$ 128) by selected variables (Continued)

\begin{tabular}{|c|c|c|c|c|c|c|}
\hline Low & 1.42 & $(0.90-2.22)$ & 0.128 & 1.65 & $(1.18-2.33)$ & 0.004 \\
\hline \multicolumn{7}{|l|}{ Stage of change } \\
\hline Maintenance & 1.00 & & & 1.00 & & \\
\hline Action & 2.17 & $(1.25-3.78)$ & 0.006 & 2.29 & $(1.54-2.41)$ & $<0.001$ \\
\hline Preparation & 2.54 & $(1.51-4.28)$ & $<0.001$ & 2.24 & $(1.56-3.23)$ & $<0.001$ \\
\hline Contemplation & 2.68 & $(1.55-4.65)$ & $<0.001$ & 2.91 & $(1.90-4.46)$ & $<0.001$ \\
\hline Precontemplation & 0.95 & $(0.53-1.69)$ & 0.856 & 1.42 & $(0.87-2.31)$ & 0.163 \\
\hline \multicolumn{7}{|c|}{ PAL perceived as sufficient } \\
\hline Yes & 1.00 & & & 1.00 & & \\
\hline No & 2.40 & $(1.72-3.37)$ & $<0.001$ & 2.95 & $(2.27-3.83)$ & $<0.001$ \\
\hline \multicolumn{7}{|c|}{$\begin{array}{l}\text { Adjusted odds ratios (OR), and their } 95 \% \text { confidence intervals }(\mathrm{Cl}) \text {, and } p \text {-values } \\
1 \text { At least one of the first-degree relatives had diabetes (type } 1 \text { or } 2) \text {. } \\
{ }^{2} \text { Systolic blood pressure } \geq 130 \mathrm{mmHg} \text { and/or diastolic blood pressure } \geq 85 \mathrm{mmHg} \text {. } \\
3 \mathrm{HDL}<1.03 \mathrm{mmol} / \mathrm{l}(\mathrm{men}),<1.29 \mathrm{mmol} / / \text { (women); } \mathrm{LDL} \geq 3 \mathrm{mmol} / \mathrm{l} \text { or/and triglycerides } \geq 1.7 \mathrm{mmol} / \mathrm{l} \text {, or medication for these lipid abnormalities. } \\
{ }^{4} \text { Normal: }<94 \mathrm{~cm}(\mathrm{~m}),<80 \mathrm{~cm}(\mathrm{w}) \text {; elevated risk: } 94-101 \mathrm{~cm}(\mathrm{~m}), 80-87 \mathrm{~cm}(\mathrm{w}) ; \text { high risk: } \geq 102 \mathrm{~cm}(\mathrm{~m}), \geq 88 \mathrm{~cm}(\mathrm{w}) . \\
5 \text { Includes occasional and regular smokers. } \\
{ }^{6} \text { Engaging in physical exercise }<30 \text { minutes three times a week. }\end{array}$} \\
\hline
\end{tabular}

units, informed consent was not collected from the participants; however, participants did receive written information on the FIN-D2D. The FIN-D2D project was not a scientific study under the legislation of the Medical Research Act in Finland, but rather an implementation study within routine primary care in Finland. Therefore, it would not in fact have been possible to collect statements of consent. Furthermore, the FIN-D2D data collection system was established by the participating hospital districts as part of normal patient records within primary health care.

\section{Results}

The mean age of the participants was $55.4(\mathrm{SD} \pm 10.23)$ years, and the mean BMI $31.3 \mathrm{~kg} / \mathrm{m}^{2}\left(\mathrm{SD} \pm 4.7 \mathrm{~kg} / \mathrm{m}^{2}\right)$ in men, and $32.1\left(\mathrm{SD}+-5.4 \mathrm{~kg} / \mathrm{m}^{2)}\right.$ in women. The majority $(64 \%)$ of the 7128 participants were women. The basic characteristics of the participants are presented in Table 1. Smoking and elevated blood pressure were significantly more prevalent among men, whereas a family history of diabetes, dyslipidaemia, and obesity were all more prevalent among women. In total, $65 \%$ of the participants were classified as physically inactive. Women rated their fitness as low more often than men. However, compared to women, men were significantly more often (40\% for men vs. $31 \%$ for women, $p<0.001$ ) in the early stages of change (precontemplation and contemplation), and men also perceived their PAL as sufficient significantly more often than women (33\% for men vs. $30 \%$ for women, $p<0.05$ ).

In total, $74 \%$ of the men and $76 \%$ of the women perceived a need to increase their PAL with no significant difference between the sexes (Table 1). As shown in Table 2, a lower education level increased the likelihood of perceiving the need to increase PAL among women (intermediate education level: OR 1.46 [95\% CI 1.01-2.09]; low education level: OR 1.49 [95\% CI 1.01-2.19]). The opposite association appeared to exist among men, but did not reach statistical significance. Other demographic factors did not make any contribution. The need to increase PAL was significantly more often perceived by men and women with high-risk waist circumference than by those with normal waist circumference. The other anthropometric or clinical risk factors did not emerge as significant determinants. Physically inactive men and women were more likely than physically active participants to perceive the need to increase their PAL. In women, lower self-rated fitness also increased the likelihood of perceiving the need to increase PAL. Furthermore, men and women at the contemplation, preparation and action stages - but not at the

Table 3 Perceived need to increase physical activity levels (PAL) by physical activity awareness categories, odds ratios (OR), $95 \%$ confidence intervals $(\mathrm{CI})$, and $p$ values by sex

\begin{tabular}{|c|c|c|c|c|c|c|}
\hline & \multicolumn{3}{|l|}{ Men } & \multicolumn{3}{|c|}{ Women } \\
\hline & OR & $95 \% \mathrm{Cl}$ & $p$ & OR & $95 \% \mathrm{Cl}$ & $p$ \\
\hline Realistic active $^{1}$ & 1.00 & & & 1.00 & & \\
\hline Overestimators $^{2}$ & 1.51 & $(1.06-2.17)$ & 0.024 & 1.79 & $(1.35-2.37)$ & $<0.001$ \\
\hline Realistic inactive ${ }^{3}$ & 7.14 & $(5.38-9.48)$ & $<0.001$ & 7.86 & $(6.37-9.70)$ & $<0.001$ \\
\hline Underestimators ${ }^{4}$ & 4.23 & $(2.92-6.14)$ & $<0.001$ & 4.68 & (3.57-6.13) & $<0.001$ \\
\hline
\end{tabular}


precontemplation stage - were significantly more likely to perceive the need to increase their PAL than those at the maintenance stage of change; the perceived need to increase PAL was most likely among the participants at the contemplation stage and least likely among the participants at the precontemplation stage. The need to increase PAL was perceived more often by participants (both men and women) who rated their PAL as insufficient than by those who perceived their PAL as sufficient.

Out of the total population, $21 \%$ of men and $20 \%$ of women were classified as realistic active, 52\% men and $55 \%$ women as realistic inactive, $13 \%$ men and $10 \%$ women as overestimators, and $14 \%$ men and $15 \%$ women as underestimators (not presented in the tables). In comparison with the realistic active participants, with regard to the three other awareness groups, the realistic inactive participants were the most likely to perceive the need to increase their PAL (Table 3). Overestimators had a significantly lower likelihood of perceiving a need to increase their PAL than realistic inactive participants.

\section{Discussion}

The vast majority of the study participants (74\% of men and $76 \%$ of women) perceived a need to increase their PAL. This reflects the high value placed on physical activity among the type 2 diabetes at-risk population, as indicated also by previous studies [12,13]. Considering the importance of increased physical activity in diabetes prevention, and the high prevalence of inactivity among the study population, the finding is promising, bearing in mind also that expression of a perceived need to change is a key component of a client's "change talk", predicting a commitment to change health behaviour $[27,28]$. Through professional advice [52] and effective counselling techniques e.g. [53] those perceiving the need to increase PAL could be encouraged to make a genuine commitment to changing their behaviour.

The present study showed that people at the contemplation stage of change, who perceived their PAL as sufficient, and who were classified as physically inactive, were more likely than others to perceive a need to increase their PAL. In addition, women who gave lower ratings to their personal physical fitness were more likely than others to perceive this need. A previous study [22] found general health and well-being, physical fitness, and weight control to be the most important determinants of a perceived need to exercise. Along similar lines, the present paper indicated a significant association between increased waist circumference and a perceived need to increase PAL in both sexes. By contrast, other type 2 diabetes risk factors did not contribute to this perception. These findings indicate the groups which are least likely to increase their PAL, and which should therefore be given particular attention within health care, in terms of endeavours towards diabetes prevention. Increased PAL would be of great benefit to individuals with a family history of diabetes, elevated blood pressure, or dyslipidaemia [8], yet the benefit does not appear to be recognised by these people. Waist circumference is an objective measure which is highly tangible for the individual, and which inevitably reflects the person's current PAL in a manner readily apparent to that individual.

Our results suggest that among the high-risk population the need to increase PAL is strongly determined by the individual's subjective perceptions. This finding is in line with the principles of the motivational interviewing approach to counselling, which emphasise the importance of listening to and reflecting individuals' perceptions if one is to evoke the motivation to change. However, clients' perceptions may easily be overlooked in a busy primary health care practice, especially if health professionals view the client as reluctant to change [54]. We would argue that if the perceptions of clients are neglected in health counselling, an important opportunity to support the client's motivation for behaviour change will remain unutilised.

Our results support previous findings on PAL awareness indicating that overestimation of one's PAL may be an obstacle to behaviour change [37,39-43]. In demonstrating a lack of any intention to change, the overestimators differed only slightly from realistic active persons, but there was a large difference between the overestimators and the realistic inactive persons. If the overestimators could be led to view their PAL realistically, they could be expected to see more clearly the need for change. Such efforts could also help to prevent incorrect tailoring in physical activity counselling [55].

As far as we know, no other studies have so far simultaneously assessed such a variety of determinants of the perceived need to increase PAL. One could expect that factors associated with a failure to perceive a need for increased PAL would be in line with determinants of the pre-contemplation stage of change. However, we found no evidence to support this presumption $[37,38,56]$. It appears that the pre-contemplation stage can best be regarded as a complex entity with its own set of determinants. It seems to be the case that some individuals at the precontemplation stage simply do not perceive the need to change their behaviours [57]. However, others perceive the need to increase their PAL in principle, yet - for whatever reason - do not consider changing their behaviour.

A previous study by Payne et al. [22] conducted among the general population $(n=286)$ found that $94 \%$ of the participants perceived the need to exercise (note that the authors did not assess the need to increase exercise, merely the need to exercise in general). It is true that the authors did not find a significant association between the perceived need and the intention or behaviour; yet the concept of 
perceived need requires further examination. Payne et al. assessed short-range intention only (the intention to exercise next week, and actual exercise behaviour a week later). Here it is worth bearing in mind that e.g. in the Diabetes Prevention Programme (DPP) [12], those who were at the contemplation stage at the baseline actually continued to increase their PAL until the 3-year (final) follow-up assessments; by contrast, other groups decreased their PAL. In fact, even six months can be regarded as a short period for changing physical activity behaviour [58-60]. The causal relationships between the perceived need to change, intentions, and behaviour should be assessed in future studies.

The study has some limitations. The study population is considered to represent the Finnish high-risk population [61]. Nevertheless, as opportunistic screening was used in the programme, there is a possibility of selection bias. The study participants were aware of their risk due to health examinations, and this aspect limits comparisons with the unaware high-risk population outside the programme. Furthermore, the assessment of the perceived need to change health behaviours was based on an evaluation form developed for the FIN-D2D intervention. The nurses were instructed to record not their own, but merely the participant's perception; however, it is possible that a persuasive style on the part of the nurse could have influenced the responses (though attempts were made to avoid such a bias through careful instruction of the nurses). Furthermore, the selfreporting method of measuring physical activity limits the assessment of PAL and PAL awareness, due to issues of recall and response bias (e.g. social desirability, inaccurate memory) and the inability of the respondent to estimate the frequency, intensity, and duration of physical activity [62]. It was due to these considerations that we did not assess lifestyle physical activity, which is often sporadic, and even more difficult to recall and report than planned, discretionary, leisure-time exercise [63]. Here it should be noted that with regard to cost, staff training, participant burden, and time, selfreporting was the only feasible method for measuring PAL in such a large implementation programme [64]. It should also be noted that the cut-off point for physically active and inactive participants was not determined according to the CDC/ACSM physical activity recommendations [65], due to the limitations of the questionnaire. However, it has been suggested [7] that the amount of physical activity needed to prevent diabetes should in fact be set at lower than the recommendations for the general adult population given by CDC/ASCM.

\section{Conclusions}

The present study shows that the vast majority of high risk individuals perceive the need to increase their PAL. However, apart from waist circumference, the perception of need appears not to be determined by the objective diabetes risk factors. Instead, the perception appears to be strongly determined by factors that are based on individuals' subjective impressions. This finding, taken together with the association between physical activity awareness and a perceived need to increase PAL, highlights the importance of listening to and reflecting clients' perceptions (which may not always be realistic), rather than focusing mainly on objective health measures. It is further important to increase clients' awareness by concretely defining the association of physical activity with all the metabolic risk factors - and with the development of diabetes. This study did not assess the predictors of behaviour change, but it does demonstrate factors worth recognising in future interventions whose aim is to facilitate the intention and commitment to change physical activity behaviour among individuals at high risk of type 2 diabetes.

\section{Competing interests}

The authors declare that they have no competing interests.

\section{Authors' contributions}

KV conceived of and designed the study, interpreted the data and drafted the manuscript. SS, JV, MV, PR and MEP participated in the design of the study. JV processed the data and performed the statistical analyses. All authors participated in interpretation of the results and critically revised subsequent versions of the paper for important intellectual content. TS, MV, MP, LN, LM, EK-H, SK-K, HO, and MEP were all in charge of the FIN-D2D concept and design, and the acquisition of the data. All the authors read and approved the final manuscript.

\section{Acknowledgements}

This work was supported by the Ministry of Social Affairs and Health; the Social Insurance Institution of Finland; the Diabetes Research Foundation of Finland; the Ministry of Education and Culture [grant numbers 121/722/2004, $45 / 627 / 2007$ to K.V] and the Juho Vainio Foundation [to K.V]. FIN-D2D was supported by hospital districts of Pirkanmaa, Southern Ostrobothnia, North Ostrobothnia, Central Finland and Northern Savo; the Finnish National Public Health Institute; the Finnish Diabetes Association; the Ministry of Social Affairs and Health in Finland, and Finland's Slot Machine Association, in cooperation with the FIN-D2D Study Group, and the Steering Committee (consisting of Huttunen J, Kesäniemi A, Kiuru S, Niskanen L, Oksa H, Pihlajamäki J. Puolakka J, Puska P, Saaristo T, Vanhala M, and Uusitupa M); the Academy of Finland [129293]; and the Commission of the European Communities, Directorate C - Public Health [2004310]. We acknowledge the help of Donald Adamson (University of Jyväskylä) in editing the manuscript.

\section{Author details}

${ }^{1}$ Department of Health Sciences, University of Jyväskylä, Jyväskylä 40014 Finland. ${ }^{2}$ Department of Sport Sciences, University of Jyväskylä, Jyväskylä 40014, Finland. ${ }^{3}$ Family Practice Unit, Central Hospital Central Finland, Jyväskylä 40620, Finland. ${ }^{4}$ Family Practice Unit, Kuopio University Hospital, Kuopio 70210, Finland. ${ }^{5}$ University of Eastern Finland, Kuopio 70211, Finland. ${ }^{6}$ Finnish Diabetes Association, Tampere 33680, Finland. ${ }^{7}$ Pirkanmaa Hospital District, Tampere 33680, Finland. ${ }^{8}$ National Institute for Health and Welfare, Helsinki 00271, Finland. ${ }^{9}$ Institute of Health Sciences, University of Oulu, Oulu 90014, Finland. ${ }^{10}$ Unit of General Practice, Oulu University Hospital, Oulu 90220, Finland. ${ }^{11}$ Health Centre of Oulu, Oulu 90100, Finland. ${ }^{12}$ Department of Internal Medicine, Seinäjoki Central Hospital, Seinäjoki 60220, Finland. ${ }^{13}$ Department of Medicine, Kuopio University Hospital, Kuopio 70210, Finland. ${ }^{14}$ Department of Medicine, Central Hospital Central Finland, Jyväskylä 40014, Finland. ${ }^{15}$ University of Eastern Finland, Kuopio 70211, Finland. ${ }^{16}$ Tampere University Hospital, Tampere 33521, Finland. 
Received: 14 December 2011 Accepted: 21 June 2012 Published: 10 July 2012

\section{References}

1. Laaksonen DE, Lindstrom J, Lakka TA, Eriksson JG, Niskanen L, Wikstrom K, Aunola S, Keinanen-Kiukaanniemi S, Laakso M, Valle T, Ilanne-Parikka P, Louheranta A, Hamalainen H, Rastas M, Salminen V, Cepaitis Z, Hakumaki M, Kaikkonen H, Harkonen P, Sundvall J, Tuomilehto J, Uusitupa M, Finnish diabetes prevention study: Physical activity in the prevention of type 2 diabetes: the Finnish diabetes prevention study. Diabetes 2005, 54:158165

2. Bassuk SS, Manson JE: Epidemiological evidence for the role of physical activity in reducing risk of type 2 diabetes and cardiovascular disease. $J$ Appl Physiol 2005, 99:1193-1204.

3. Warburton DE, Nicol CW, Bredin SS: Health benefits of physical activity: the evidence. CMAJ 2006, 174:801-809.

4. Hu G, Qiao Q, Silventoinen K, Eriksson JG, Jousilahti P, Lindstrom J, Valle TT Nissinen A, Tuomilehto J: Occupational, commuting, and leisure-time physical activity in relation to risk for Type 2 diabetes in middle-aged Finnish men and women. Diabetologia 2003, 46:322-329.

5. Borodulin K, Tuomilehto J, Peltonen M, Lakka TA, Sundvall J, Jousilahti P: Association of leisure time physical activity and abdominal obesity with fasting serum insulin and 2-h postchallenge plasma glucose levels. Diabet Med 2006, 23:1025-1028.

6. Healy GN, Dunstan DW, Salmon J, Cerin E, Shaw JE, Zimmet PZ, Owen N Objectively measured light-intensity physical activity is independently associated with 2-h plasma glucose. Diabetes Care 2007, 30:1384-1389.

7. Waller K, Kaprio J, Lehtovirta M, Silventoinen K, Koskenvuo M, Kujala UM: Leisure-time physical activity and type 2 diabetes during a 28 year follow-up in twins. Diabetologia 2010, 53:2531-2537.

8. LaMonte MJ, Blair SN, Church TS: Physical activity and diabetes prevention. J Appl Physiol 2005, 99:1205-1213.

9. Boyle RG, O'Connor PJ, Pronk NP, Tan A: Stages of change for physical activity, diet, and smoking among HMO members with chronic conditions. Am J Health Promot 1998, 12:170-175.

10. Brewer NT, Chapman GB, Gibbons FX, Gerard M, McCaul KD, Weinstein ND: Meta-analysis of the relationship between risk perception and health behavior: The example of vaccination. Health Psychol 2007, 26:136-145.

11. Kim C, Mc Ewen LN, Piette JD, Goewey J, Ferrara A, Walker E: Risk perception for diabetes among women with histories of gestational diabetes mellitus. Diabetes Care 2007, 30:2281-2286.

12. Delahanty LM, Conroy MB, Nathan DM, Diabetes Prevention Program Research Group: Psychological predictors of physical activity in the diabetes prevention program. J Am Diet Assoc 2006, 106:698-705.

13. Centers for Disease Control and Prevention (CDC): Self-reported prediabetes and risk-reduction activities--United States, 2006. MMWR Morb Mortal Wkly Rep 2008, 57:1203-1205.

14. Blue CL: Does the theory of planned behavior identify diabetes-related cognitions for intention to be physically active and eat a healthy diet? Public Health Nurs 2007, 24:141-150.

15. Hivert MF, Warner AS, Shrader P, Grant RW, Meigs JB: Diabetes risk perception and intention to adopt healthy lifestyles among primary care patients. Diabetes Care 2009, 32:1820-1822.

16. Prochaska JO, Norcross JC: Systems of psychotherapy. A Transtheoretical analysis. 7th edition. Belmont, CA: Brooks/Cole; 2010.

17. Miller WR, Rose GS: Toward a theory of motivational interviewing. Am Psychol 2009, 64:527-537.

18. Hettema J, Steele J, Miller WR: Motivational interviewing. Annu Rev Clin Psychol 2005, 1:91-111.

19. Paisley CM, Sparks P: Expectations of reducing fat intake: the role of perceived need within the theory of planned behaviour. Psychol Health 1998, 13:341-353.

20. Povey R, Conner M, Sparks P, James R, Shepherd R: Application of the theory of planned behaviour to two dietary behaviours: roles of perceived control and self-efficacy. Br J Health Psychol 2000, 5:121-139.

21. Raats MM, Sparks $P$, James R, Shepherd R: Understanding dietary change: Perceptions of ten dietary changes. Proc Nutr Soc 1996, 55:1A-77A

22. Payne $N$, Jones $F$, Harris PR: The role of perceived need within the theory of planned behaviour: a comparison of exercise and healthy eating. $\mathrm{Br}$ Health Psychol 2004, 9(Pt 4):489-504.
23. Ajzen I: The theory of planned behaviour. Organ Behav Hum Decis Process 1991, 50:179-211.

24. Prochaska JO, DiClemente CC: Stages and processes of self-change of smoking: toward an integrative model of achange. J Consult Clin Psychol 1983, 51:390-395.

25. Miller WR, Rollnick S: Motivational interviewing: preparing people for change. 2nd edition. New York: Guilford Press; 2002.

26. Amrhein PC, Miller WR, Yahne CE, Palmer M, Fulcher L: Client commitment language during motivational interviewing predicts drug use outcomes. J Consult Clin Psychol 2003, 71:862-878.

27. Moyers TB, Martin T, Christopher PJ, Houck JM, Tonigan JS, Amrhein PC: Client language as a mediator of motivational interviewing efficacy: where is the evidence? Alcohol Clin Exp Res 2007, 31(10 Suppl):40s-47s

28. Apodaca TR, Longabaugh R: Mechanisms of change in motivational interviewing: a review and preliminary evaluation of the evidence. Addiction 2009, 104:705-715.

29. Hardcastle S, Taylor A, Bailey M, Castle R: A randomised controlled trial on the effectiveness of a primary health care based counselling intervention on physical activity, diet and CHD risk factors. Patient Educ Couns 2008, 70:31-39.

30. Bennett JA, Lyons KS, Winters-Stone K, Nail LM, Scherer J: Motivational interviewing to increase physical activity in long-term cancer survivors: a randomized controlled trial. Nurs Res 2007, 56:18-27.

31. Brodie DA, Inoue A: Motivational interviewing to promote physical activity for people with chronic heart failure. J Adv Nurs 2005, 50:518-527.

32. Harland J, White M, Drinkwater C, Chinn D, Farr L, Howel D: The Newcastle exercise project: a randomised controlled trial of methods to promote physical activity in primary care. Br Med J 1999, 319:828-832.

33. Hutchison AJ, Breckon JD, Johnston LH: Physical activity behavior change interventions based on the transtheoretical model: a systematic review. Health Educ Behav 2009, 36:829-845.

34. Spencer L, Adams TB, Malone S, Roy L, Yost E: Applying the transtheoretical model to exercise: a systematic and comprehensive review of the literature. Health Promot Pract 2006, 7:428-443.

35. Carino J , Coke L, Gulanic M: Using motivational interviewing to reduce diabetes risk. Prog Cardiovasc Nurs 2004, 19:149-154.

36. Penn L, White M, Oldroyd J, Walker M, Alberti KG, Mathers JC: Prevention of type 2 diabetes in adults with impaired glucose tolerance: the European Diabetes Prevention RCT in Newcastle upon Tyne, UK. BMC Public Health 2009, 9:342.

37. Ronda G, Van Assema P, Brug J: Stages of change, psychological factors and awareness of physical activity levels in The Netherlands. Health Promot Int 2001, 16:305-314.

38. Garber CE, Allsworth JE, Marcus BH, Hesser J, Lapane KL: Correlates of the stages of change for physical activity in a population survey. Am J Public Health 2008, 98:897-904.

39. De Ridder $C$, Lechner $L$ : Overschatting van het eigen bewegingsgedrag: gevolgen voor determinanten en stage of change. Tijdschrift Sociale Gezondheidszorg 2004, 79:346-355.

40. van Sluijs EM, Griffin SJ, van Poppel MN: A cross-sectional study of awareness of physical activity: associations with personal, behavioral and psychosocial factors. Int J Behav Nutr Phys Act 2007, 4:53.

41. Watkinson C, van Sluijs EM, Sutton S, Hardeman W, Corder K, Griffin SJ: Overestimation of physical activity level is associated with lower BMI: a cross-sectional analysis. Int J Behav Nutr Phys Act 2010, 7:68.

42. Lechner L, Bolman C, Van Dijke M: Factors related to misperception of physical activity in The Netherlands and implications for health promotion programmes. Health Promot Int 2006, 21:104-112.

43. Corder K, van Sluijs EM, McMinn AM, Ekelund U, Cassidy A, Griffin SJ: Perception versus reality awareness of physical activity levels of British children. Am J Prev Med 2010, 38:1-8

44. Finnish Diabetes Association: Programme for the Prevention of Type 2 Diabetes in Finland 2003-2010:: Gummerus Printing, Jyväskylä: Finnish Diabetes Association; 2003.

45. Finnish Diabetes Association: Dehkon 2D-hanke (D2D) 2003-2007. Loppuraportti. In Finnish. Kirjapaino Hermes Oy: Finnish Diabetes Association; 2009.

46. Saaristo T, Peltonen M, Keinanen-Kiukaanniemi S, Vanhala M, Saltevo J, Niskanen L, Oksa H, Korpi-Hyövälti E, Tuomilehto J, FIN-D2D Study Group: National type 2 diabetes prevention programme in Finland: FIN-D2D. Int J Circumpolar Health 2007, 66:101-112. 
47. Saaristo T, Moilanen L, Korpi-Hyovalti E, Vanhala M, Saltevo J, Niskanen L, Jokelainen J, Peltonen M, Oksa H, Tuomilehto J, Uusitupa M, KeinanenKiukaanniemi S: Lifestyle intervention for prevention of type 2 diabetes in primary health care: one-year follow-up of the Finnish National Diabetes Prevention Program (FIN-D2D). Diabetes Care 2010, 33:2146-2151.

48. Lindstrom J, Tuomilehto J: The diabetes risk score: a practical tool to predict type 2 diabetes risk. Diabetes Care 2003, 26:725-731.

49. World Health Organisation: Definition, Diagnosis and Classification of Diabetes Mellitus and Its complications. Report of a Who Consultation. Part 1: Diagnosis and Classification of Diabetes Mellitus.; 1999. 99.2.

50. Graham I, Atar D, Borch-Johnsen K, Boysen G, Burell G, Cifkova R, Dallongeville J, De Backer G, Ebrahim S, Gjelsvik B, Herrmann-Lingen C, Hoes A, Humphries S, Knapton M, Perk J, Priori SG, Pyorala K, Reiner Z, Ruilope L, Sans-Menendez S, Op Reimer WS, Weissberg P, Wood D, Yarnell J, Zamorano JL, Walma E, Fitzgerald T, Cooney MT, Dudina A, Vahanian A, et al: European guidelines on cardiovascular disease prevention in clinical practice: full text. Fourth Joint Task Force of the European Society of Cardiology and other societies on cardiovascular disease prevention in clinical practice (constituted by representatives of nine societies and by invited experts). Eur J Cardiovasc Prev Rehabil 2007, 14(Suppl 2):S1-S113.

51. Alberti KG, Zimmet P, Shaw J: International Diabetes Federation: a consensus on Type 2 diabetes prevention. Diabet Med 2007, 24:451-463.

52. Geiss LS, James C, Gregg EW, Albright A, Williamson DF, Cowie CC: Diabetes risk reduction behaviors among U.S. adults with prediabetes. Am J Prev Med 2010, 38:403-409.

53. Williams SL, French DP: What are the most effective intervention techniques for changing physical activity self-efficacy and physical activity behaviour-and are they the same? Health Educ Res 2011, 26:308-322.

54. Jallinoja P, Absetz P, Kuronen R, Nissinen A, Talja M, Uutela A, Patja K: The dilemma of patient responsibility for lifestyle change: perceptions among primary care physicians and nurses. Scand J Prim Health Care 2007, 25:244-249.

55. Noar SM, Benac CN, Harris MS: Does tailoring matter? Meta-analytic review of tailored print health behavior change interventions. Psychol Bull 2007, 133:673-693

56. Lorentzen C, Ommundsen Y, Holme I: Psychosocial correlates of stages of change in physical activity in an adult community sample DOI:dx.doi. org. Eur J Sport Sci 2007, 7:93-106.

57. Miilunpalo S, Nupponen R, Laitakari J, Marttila J, Parosnen O: Stages of change in two modes of health-enhancing physical activity: methodological aspects and promotional implications. Health Educ Res 2000, 15:435-448.

58. Marcus BH, Forsyth LH, Stone EJ, Dubbert PM, McKenzie TL, Dunn AL, Blair SN: Physical activity behaviour change: issues in adoption and maintenance. Health Psychol 2000, 19(Suppl 1):32-41.

59. Marcus BH, Williams DM, Dubbert PM, Sallis JF, King AC, Yancey AK, Franklin BA, Buchner D, Daniels SR, Claytor RP, American Heart Association Council on Nutrition, Physical Activity, and Metabolism (Subcommittee on Physical Activity), American Heart Association Council on Cardiovascular Disease in the Young, Interdisciplinary Working Group on Quality of Care and Outcomes Research: Physical activity intervention studies: what we know and what we need to know: a scientific statement from the American Heart Association Council on Nutrition, Physical Activity, and Metabolism (Subcommittee on Physical Activity); Council on Cardiovascular Disease in the Young; and the Interdisciplinary Working Group on Quality of Care and Outcomes Research. Circulation 2006, 114:2739-2752.

60. Foster $C$, Hillsdon $M$, Thorogood M: Interventions for promoting physical activity. Cochrane Database Syst Rev 2009, 1. doi:10.1002/14651858. CD003180.pub2.

61. Saaristo T: Assessment of risk and prevention of type 2 diabetes in primary health care. 2011. PhD thesis. Acta Universitas Ouluensis D1144, University of Oulu.

62. Shephard RJ: Limits to the measurement of habitual physical activity by questionnaires. Br J Sports Med 2003, 37:197-206. discussion 206.

63. Troiano RP, Pettee Gabriel KK, Welk GJ, Owen N, Sternfeld B: Reported physical activity and sedentary behaviour: why do you ask? J Phys Act Health 2012, 9(Suppl 1):S68-S72.

64. Hooker SP, Fulton J, Mudd LM: Practice-based evidence: A novel concept for self-report physical activity measurement. J Phys Act Health 2012, 9(Suppl 1):S85-S87.
65. Haskell WL, Lee IM, Pate RR, Powell KE, Blair SN, Franklin BA, Macera CA, Heath W, Thompson PD, Bauman A: Physical activity and public health: updated recommendation for adults from the American College of Sports Medicine and the American Heart Association. Med Sci Sports Exerc 2007, 39:1423-1434.

doi:10.1186/1471-2458-12-514

Cite this article as: Vähäsarja et al:: Perceived need to increase physical activity levels among adults at high risk of type 2 diabetes. A crosssectional analysis within a community-based diabetes prevention project FIN-D2D. BMC Public Health 2012 12:514.

\section{Submit your next manuscript to BioMed Central and take full advantage of:}

- Convenient online submission

- Thorough peer review

- No space constraints or color figure charges

- Immediate publication on acceptance

- Inclusion in PubMed, CAS, Scopus and Google Scholar

- Research which is freely available for redistribution

Submit your manuscript at www.biomedcentral.com/submit
C) Biomed Central 